\title{
Hyperthermia Induces Age-Dependent Changes in Rat Hippocampal Excitability
}

\author{
Michelle T. Liebregts, MSc, ${ }^{1}$ Richard S. McLachlan, MD, FRCPC, ${ }^{1,2,3}$ and L. Stan Leung, $\mathrm{PhD}^{1,2,3}$
}

\begin{abstract}
The mechanisms underlying the generation of febrile seizures are poorly understood. This study investigated hyperthermia-induced changes in the hippocampus, a structure implicated in febrile seizures. It was hypothesized that neuronal excitability in the hippocampus changes with increasing temperature, and that this change is different in adult as compared with immature rats. Adult and immature (15-17 days postnatal) male rats were studied under urethane anesthesia during normothermia, moderate hyperthermia $\left(38-39.5^{\circ} \mathrm{C}\right)$, and severe hyperthermia $\left(>39.5^{\circ} \mathrm{C}\right)$. Paired-pulse inhibition of the orthodromically activated population spikes in the dentate gyrus and cornu ammonis 1 region of the hippocampus (CA1), two structures within the hippocampus, was measured after stimulation of the medial perforant path and Schaffer collaterals, respectively. In the adult rat, paired-pulse inhibition was increased in the dentate gyrus during moderate and severe hyperthermia but decreased in CA1 during severe hyperthermia (all $p$ values $<0.05$ ). In the immature rat, paired-pulse inhibition was unchanged in the dentate gyrus but decreased in CA1 during moderate hyperthermia $(p<0.05)$. We suggest that hyperthermia contributes to seizure susceptibility in the immature hippocampus by decreasing CA1 inhibition. In the adult rat, a decrease in CA1 inhibition requires a higher degree of hyperthermia, and hippocampal seizure generation is opposed by an increase in dentate gyrus inhibition.
\end{abstract}

Ann Neurol 2002;52:318-326

Seizures occur more readily in the immature than the mature brain, ${ }^{1}$ and febrile seizures are the most common seizure type in children before the age of 5 years. ${ }^{2,3}$ Whether febrile seizures have detrimental consequences is being disputed, ${ }^{3,4}$ one possible consequence being temporal lobe sclerosis and temporal lobe epilepsy. ${ }^{5,6}$ Prolonged febrile convulsions have been suggested to induce hippocampal cell loss in infants. ${ }^{7}$ Febrile seizures in rats result in a persistent increase in seizure susceptibility ${ }^{8-11}$ and neuronal excitability ${ }^{12,13}$ and alterations in behavior. ${ }^{14}$ However, there is little pathology in the adult rats after febrile seizures. ${ }^{15,16}$

The mechanisms underlying hyperthermia-induced seizure are not known. An increase in temperature increases excitatory postsynaptic potentials (EPSPs) in the hippocampus of different preparations, accompanied by a paradoxical decrease in the population spike. ${ }^{17-19}$ A population spike is an extracellular potential generated by synchronous firing of action potentials in a population of neurons. ${ }^{20}$ The decrease in the population spike amplitude with temperature could be explained by a shorter spike duration at high temperature. Heating from 27 to $37^{\circ} \mathrm{C}$ increased the early inhibitory postsynaptic potentials (IPSPs) of hippocam- pal cornu ammonis 1 region of the hippocampus (CA1) neurons in vitro. ${ }^{21}$ However, the late IPSPs (presumably $\mathrm{K}^{+}$mediated) and the spike after hyperpolarization decreased with temperature. ${ }^{21}$

We are not aware of in vivo studies on inhibition change with hyperthermia. Thus, in this study, we used a paired-pulse paradigm to assess the neuronal inhibition in the hippocampus during hyperthermia in anesthetized rats in vivo. Pairs of orthodromic stimulus pulses were delivered to activate the dentate gyrus (DG) and CA1 of the hippocampus, and the ratio of the evoked population spikes is used as a measure of inhibition. ${ }^{22,23}$ We hypothesized that paired-pulse inhibition in the hippocampus changes with increasing temperature, and that this change in inhibition is different in adult and immature rats. Some of the results were reported in an abstract. ${ }^{24}$

\section{Materials and Methods \\ Animal Preparation, Electrode Placement, and Data Collection}

Procedures were approved by the Animal Use Committee at the University of Western Ontario. Adult (6-12 weeks) and immature (15-17 days postnatal) male Long-Evans rats were
From the ${ }^{1}$ Graduate Program in Neuroscience, and Departments of ${ }^{2}$ Physiology and ${ }^{3}$ Clinical Neurological Sciences, University of Western Ontario, London, Ontario, Canada.

Received May 29, 2001, and in revised form Feb 18 and Apr 23, 2002. Accepted for publication Apr 23, 2002.
Current address for Dr McLachlan: Shaikh Khalifa Medical Center, P.O. Box 51900, Abu Dhabi, United Arab Emirates.

Address correspondence to Dr Leung, Department of Clinical Neurological Sciences, University Campus, London Health Sciences Centre, University of Western Ontario, London, Ontario, Canada N6A 5A5. E-mail: sleung@uwo.ca 
anesthetized with 1.2 to $1.3 \mathrm{gm} / \mathrm{kg}$ of urethane intraperitoneally. Based on the times of growth spurts, rats that are 15 to 17 days postnatal may be considered to be equivalent to a child younger than 3 years old. ${ }^{25}$ Atropine methylnitrate $(0.12-0.17 \mathrm{mg} / \mathrm{kg}$ IP) was given to prevent fluid accumulation in the airway. A rat then was placed in a stereotaxic instrument, with age-appropriate ear and nose bar adaptors (Kopf, Tujunga, CA). Temperature was monitored using a calibrated rectal thermal probe and maintained at 36.5 to $37.5^{\circ} \mathrm{C}$ by an electric heat pad on the under body (Frederick Haer, Bowdoinham, ME).

Recording electrodes were glass micropipettes filled with $2 \mathrm{M}$ sodium acetate and $4 \%$ pontamine sky blue $(5-15 \mathrm{M} \Omega)$; a silver wire sutured under the skin near the back of the neck was used as the reference. A stimulating electrode was placed in the medial perforant pathway (MPP) to orthodromically activate the dentate granule cells. The $\operatorname{target}^{26,27}$ for the MPP stimulating electrode was posterior $8 \mathrm{~mm}$ and lateral $4 \mathrm{~mm}$ in adult rats, and posterior $6.4 \mathrm{~mm}$ and lateral $2.7 \mathrm{~mm}$ in immature rats. Evoked field potentials were recorded at the DG granule cell layer, ${ }^{26,27}$ posterior $4.8 \mathrm{~mm}$ and lateral $3.5 \mathrm{~mm}$ (adult) and posterior $3.7 \mathrm{~mm}$ and lateral $2.4 \mathrm{~mm}$ (immature). A second stimulating electrode was placed in CA3 to orthodromically activate CA1 through the Schaffer collaterals, with a target of posterior $3.2 \mathrm{~mm}$ and lateral $3.2 \mathrm{~mm}$ (adult), ${ }^{26}$ and posterior $2.8 \mathrm{~mm}$ and lateral $3.2 \mathrm{~mm}$ (immature). ${ }^{27}$ The recording electrode was lowered to the CA1 pyramidal cell layer at posterior $3.5 \mathrm{~mm}$ and lateral $2.4 \mathrm{~mm}$ (adult) and posterior $2.8 \mathrm{~mm}$ and lateral $3.2 \mathrm{~mm}$ (immature). ${ }^{26,27}$ A small jeweler's screw placed in the frontal skull served as a stimulus anode. All electrodes were placed in the right hippocampus, at 2.5 to $4 \mathrm{~mm}$ below the skull surface. The final electrode positions were determined by optimizing the response after small movements of the stimulating electrode and then maximizing the amplitude of the evoked population spike. ${ }^{28}$ At the end of each experiment, the locations of the stimulating and recording electrodes were marked, respectively, by lesion or dye. The rat was perfused intracardially with $10 \%$ formalin in phosphate buffer. The rat's brain was removed and subsequently sectioned and stained with thionin, and the electrode locations were verified.

Brain temperature was measured by a thermistor (Fenwal GA51M2, Pawtucket, RI or YSI 44007, Dayton, OH) placed in CA1. Simultaneously recorded brain and rectal temperatures were found to differ by less than $0.4^{\circ} \mathrm{C}$, and the absolute difference between brain and rectal temperatures averaged $0.15 \pm 0.01^{\circ} \mathrm{C}$ in four adult rats and $0.19 \pm$ $0.03^{\circ} \mathrm{C}$ in three immature rats $(>20$ measures were made, evenly dispersed over $36-42^{\circ} \mathrm{C}$ ). Thus, only rectal temperature was measured routinely and reported below, and rats with concomitant brain temperature and electrophysiological recordings were excluded from the results.

After placement of the electrodes, a rest period of more than 15 minutes was allowed for responses to stabilize. Field potentials were amplified, digitized at $10 \mathrm{kHz}$ using a custom program. Paired-pulse stimuli, repeated at greater than 8 -second intervals, were delivered to MPP with an interpulse interval (IPI) of 20, 30, 50, 100, 150, 200, or 400 milliseconds, at a stimulus intensity of three times the P1 threshold. Paired pulses of 20 to 400 milliseconds IPI then were delivered to CA3. Four sweeps were averaged and stored on a microcomputer. Responses also were collected at five stimulus intensity levels (one through five times the first-pulse population spike threshold, determined for each rat under normothermic conditions), with a fixed IPI of 20 milliseconds for MPP and 30 milliseconds for CA3 stimulation.

\section{Hyperthermia Treatment}

The normal physiological basal body temperature for an adult or immature rat was 36.5 to $37.5^{\circ} \mathrm{C}$ (mean, $36.7^{\circ} \mathrm{C}$ ). After baseline recordings during normothermia, the rat was heated by the heating pad to attain two hyperthermic conditions operationally defined as (1) moderate hyperthermia, with an average rectal temperature of $38.8^{\circ} \mathrm{C}$ (range, $38-$ $39.3^{\circ} \mathrm{C}$ ), and (2) severe hyperthermia, with an average rectal temperature of $40^{\circ} \mathrm{C}$ (range, $39.5-40.7^{\circ} \mathrm{C}$ ). Severe hyperthermia was not induced in the immature rats because during preliminary experiments the immature rats usually did not survive this condition. This was likely a combined effect of anesthetic and hyperthermia, because unanesthetized immature rats survived hyperthermia better than older rats. ${ }^{9}$ The rate of heating was approximately $0.19^{\circ} \mathrm{C}$ per minute for adult rats and $0.37^{\circ} \mathrm{C}$ per minute for immature rats. The temperature was stabilized at each hyperthermic condition for 10 minutes before electrophysiological recordings. The animals were cooled by placing a thin ice pack under their ventral body surface. After cooling to normothermic temperature, an additional recovery period of at least 30 minutes was allowed before the "return to normothermia" set of data was collected. Ten adult rats and eight immature rats went through the complete heating and cooling procedures. Not all rats had both DG and CA1 recordings, because one of these targets could have been occasionally missed.

\section{Data Measurement and Analysis}

Population spike amplitude was measured from spike onset to its peak negativity ${ }^{28}$ (Fig 1, inset). P1 and P2 are the population spike amplitudes following the first and the second pulse respectively. The ratio of $\mathrm{P} 2$ to $\mathrm{P} 1$ was calculated as an index of the paired-pulse response. The onset and peak latency of the population spike were measured from the peak of the stimulus artifact. The rate of increase of the population $\mathrm{EPSP}^{28}$ was taken as the slope at two fixed latencies before the onset of the population spike (see Fig 1, inset). E1 and E2 are the population EPSP slopes following the first and the second pulse respectively. In all cases, measurements were taken at least 0.2 milliseconds before the onset of the population spike. Because of the shift along the $x$ axis with increasing temperature, the more standard procedure of using fixed latencies from the stimulus artifact was not possible.

The statistical significance of different experimental measures was estimated with repeated measures analysis of variance (ANOVA), using the Greenhouse-Geisser conservative-F, including all conditions for a group of rats. There were four conditions for adults, normothermia, moderate hyperthermia, severe hyperthermia, and return to normothermia, and three conditions for immature rats, normothermia, moderate hyperthermia, and return to normothermia. A significant ANOVA 


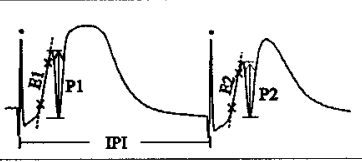

A

\section{Adult}

DG

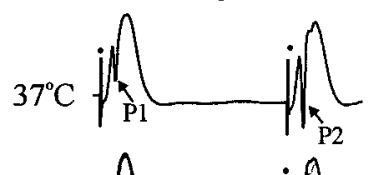<smiles>CC1C=CCC=C1</smiles><smiles>CC1CCCCC1(C)C</smiles>

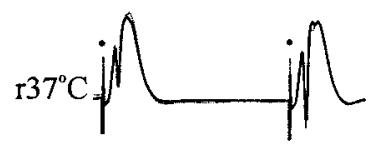<smiles>C=CCC(C)CCC</smiles>

B

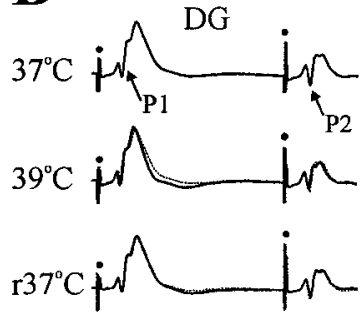

Immature

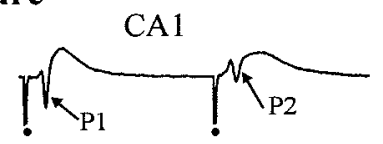<smiles>C=CC=CC</smiles><smiles>CCCCC(C)CCC(C)C</smiles>

Fig 1. Hyperthermia affects differentially the paired-pulse responses in the dentate gyrus $(D G)$ and cornu ammonis 1 region of the hippocampus (CA1) of the adult and immature hippocampus. Representative average evoked potentials $(n=$ 4) were recorded at the $D G$ granule cell layer after medial perforant path stimulation, or at the CA1 pyramidal cell layer after CA3 stimulation. Stimulus intensities were three times the threshold of the population spike. Inset shows measurement of the slopes of the population EPSPS (E1 and E2 after the first and the second pulse, respectively) and the population spikes (P1 and P2 after the first and the second pulse, respectively). (A) Hyperthermia decreased $P 2$ in the DG and increased it in the CA1. Temperatures were $37^{\circ} \mathrm{C}$ (normothermia), $39^{\circ} \mathrm{C}$ (moderate hyperthermia), and $40^{\circ} \mathrm{C}$ (severe hyperthermia), and $r 37^{\circ} \mathrm{C}$ (return to normothermia). The overlying, dotted trace is the normothermia response. (B) Similar average evoked potentials are shown for representative immature rats before and after moderate hyperthermia $\left(39^{\circ} \mathrm{C}\right)$. Moderate hyperthermia did not affect responses (shown at 50 milliseconds IPI) in the DG but increased P2 in CA1. (dots) Stimulus artifact; $m s=$ milliseconds.

was followed by Tukey's post hoc test using the unadjusted degrees of freedom. In data sets involving a covariate, a repeated measures analysis of covariance (ANCOVA) was used.
Bivariate regression analysis was used to examine the relationship between brain and rectal temperature. Statistical significance was set at $p$ value less than 0.05 . Rats with incomplete data sets in the 20 to 200 -millisecond IPI range were omitted

Fig 2. Paired-pulse inhibition of the population spikes in adult dentate gyrus (DG) was increased during hyperthermia. (A) Group data showing the P2 to P1 ratio as a function of the interpulse interval (IPI); a medial perforant pathway stimulus intensity of three times the P1 threshold was used. P2/P1 significantly decreased during moderate hyperthermia $(\mathrm{p}<$ $0.05)$ and severe hyperthermia $(\mathrm{p}<0.01)$ at IPIs of 20 to 200 milliseconds $(n=8)$ but not at 400 milliseconds IPI, as compared with normothermia. Thin horizontal solid line at $P 2 / P 1=1$ is provided for reference. Error bars represent 1 standard error of the mean. (B) The change in P2 amplitude was independent of the change in P1 amplitude. Scatter plots of $P 2$ versus $P 1$ are shown for each of the four conditions: normothermia, moderate hyperthermia, severe hyperthermia, and "return to normothermia." Each point represents an average response evoked with a stimulus intensity of three times P1 threshold and 20 milliseconds IPI. The best linear regression fit was made for each of the four conditions. $m s=$ milliseconds.

\section{A \\ Adult DG}

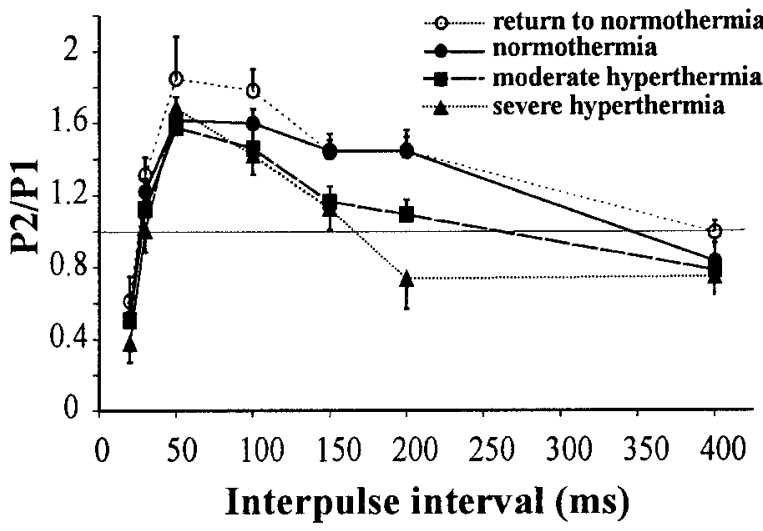

B

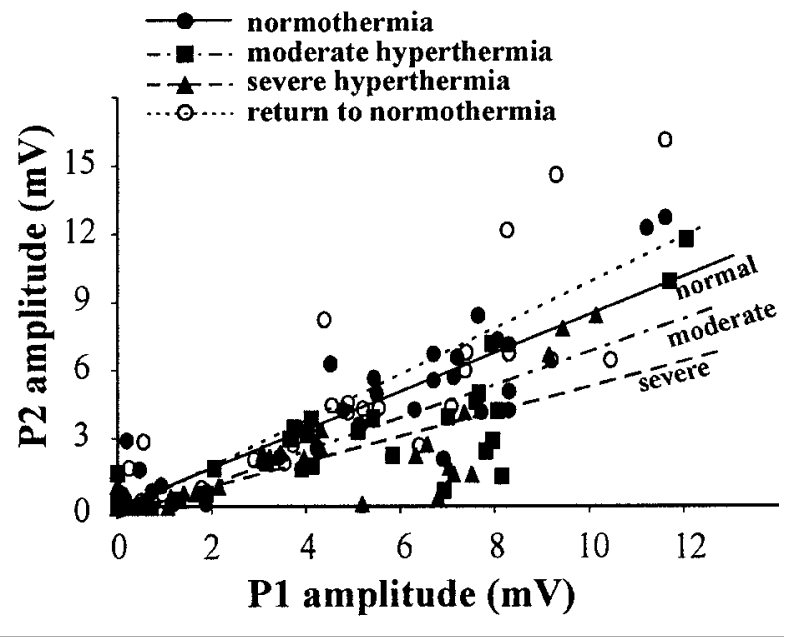


from the analysis. Data at 400 milliseconds IPI were collected for fewer rats than data at 20 to 200 milliseconds IPI. Because of the smaller sample size, separate analyses were conducted for the 400-millisecond IPI data.

\section{Results}

Hyperthermia Increased Paired-pulse Inhibition in the Adult Dentate Gyrus

Stimulation of the MPP resulted in a slow positive wave in the DG granule cell layer that was interpreted as the population EPSP, and a sharp negative wave interpreted as the population spike. The mean stimulus intensities required to elicit a detectable EPSP and population spike in the adult DG were $24 \pm 8 \mu \mathrm{A}$ and $147 \pm 29 \mu \mathrm{A}$, respectively (mean \pm standard error of the mean; $\mathrm{n}=8$ ). Paired-pulse stimulation showed a triphasic relation of the $\mathrm{P} 2$ to $\mathrm{P} 1$ ratio with the IPI during normothermia (Fig 2A). Paired-pulse inhibition (ie, P2/P1, < 1) was found at IPI less than 50 milliseconds and IPI greater than 200 milliseconds, with paired-pulse facilitation (ie, P2/P1, > 1) between 50 and 200 milliseconds IPI (see Figs 1A and 2A).

Hyperthermia had a significant effect in decreasing $\mathrm{P} 2 / \mathrm{P} 1$ in the adult DG. This was most striking at 200 milliseconds IPI, where P2/P1 was greater than 1 during normothermia but less than 1 during severe hyperthermia (see Fig 2A). A two-factor (group $\times$ IPI) repeated measures ANOVA showed a significant main effect of temperature on $\mathrm{P} 2 / \mathrm{P} 1 \quad\left(\mathrm{~F}_{2,12}=8.04 ; p=\right.$ $0.007)$ with no significant interaction between temperature and IPI. Tukey's post hoc test showed that the decrease in $\mathrm{P} 2 / \mathrm{P} 1$ was significant during moderate $\left(\mathrm{q}_{4,21}=2.80 ; p<0.05\right)$ and severe $\left(\mathrm{q}_{4,21}=4.53\right.$; $p<0.01)$ hyperthermia, as compared with normothermia. No significant difference in $\mathrm{P} 2 / \mathrm{P} 1 \quad(p>0.05)$ was found between moderate and severe hyperthermia, or between normothermia and "return to normothermia." A separate one-factor repeated measures ANOVA showed no significant difference in P2/P1 during hyperthermia at an IPI of 400 milliseconds $(n=6)$.

\section{Hyperthermia Significantly Decreased P2 \\ Independently of P1 in the Adult Dentate Gyrus}

In the adult DG, hyperthermia did not have a significant effect on the amplitude of $\mathrm{P} 1$ at a fixed stimulus intensity of three times the P1 threshold (Table 1). Thus, the effect of temperature on the P2 to P1 ratio was essentially the same as that of temperature on P2 alone (not shown). The input-output data (using different stimulus intensities; $n=6$ ) confirmed the overall lack of a main effect of temperature on $\mathrm{P} 1\left(\mathrm{~F}_{3,12}=\right.$ 3.4; $p=0.066$ ). However, there was a significant interaction between temperature and stimulus intensity $\left(\mathrm{F}_{3,15}=3.33 ; p=0.048\right)$. Tukey's post hoc test showed that P1 amplitude was significantly decreased during severe hyperthermia as compared with normothermia at four and five times threshold (both with $\mathrm{q}_{4,23}=3.3 ; p<0.01$ ).

The decrease in P2 amplitude in the adult DG with temperature was independent of P1 amplitude, as shown by repeated measures ANCOVA $(n=6)$. For the same P1, the amplitude of P2 (at a fixed IPI of 20 milliseconds) was significantly decreased during moderate $\left(\mathrm{F}_{1,28}=32.1 ; p<0.0001\right)$ or severe hyperthermia $\left(\mathrm{F}_{1,28}=31.5 ; p<0.0001\right)$, as compared with normothermia (see Fig 2B). There was no significant difference between normothermia and return to normothermia $\left(\mathrm{F}_{1,28}=3.16 ; p=0.086\right)$.

Table 1. Effect of Hyperthermia on the Onset Latency and the Peak Amplitude of the Population Spike (P1) Evoked by the First Stimulus Pulse in the DG and CA1 of Adult and Immature Rats

\begin{tabular}{|c|c|c|c|c|}
\hline \multirow[b]{2}{*}{ Effect } & \multicolumn{2}{|c|}{ Adult } & \multicolumn{2}{|c|}{ Immature } \\
\hline & $\mathrm{DG}(\mathrm{n}=8)$ & $\begin{array}{c}\text { CA1 } \\
(\mathrm{n}=10)\end{array}$ & $\mathrm{DG}(\mathrm{n}=6)$ & $\begin{array}{c}\text { CA1 } \\
(\mathrm{n}=8)\end{array}$ \\
\hline \multicolumn{5}{|l|}{ P1 onset latency (msec) } \\
\hline Normothermia & $3.10 \pm 0.10$ & $5.67 \pm 0.54$ & $5.22 \pm 0.34$ & $4.99 \pm 0.41$ \\
\hline Moderate hyperthermia & $2.79 \pm 0.08^{\mathrm{a}}$ & $5.30 \pm 0.52^{\mathrm{a}}$ & $4.74 \pm 0.34^{\mathrm{a}}$ & $4.70 \pm 0.42^{\mathrm{a}}$ \\
\hline Severe hyperthermia & $2.60 \pm 0.06^{\mathrm{a}}$ & $5.13 \pm 0.53^{\mathrm{a}}$ & N/A & N/A \\
\hline Return to normothermia & $2.95 \pm 0.06^{\mathrm{a}}$ & $5.63 \pm 0.53$ & $5.38 \pm 0.36$ & $5.17 \pm 0.43^{\mathrm{b}}$ \\
\hline \multicolumn{5}{|l|}{ P1 amplitude (mV) } \\
\hline Normothermia & $6.73 \pm 0.87$ & $8.79 \pm 0.97$ & $1.09 \pm 0.30$ & $3.73 \pm 0.88$ \\
\hline Moderate hyperthermia & $6.78 \pm 1.25$ & $7.13 \pm 0.98^{\mathrm{a}}$ & $0.785 \pm 0.24$ & $2.61 \pm 0.77^{\mathrm{a}}$ \\
\hline Severe hyperthermia & $6.27 \pm 1.26$ & $5.47 \pm 0.94^{\mathrm{a}}$ & N/A & N/A \\
\hline Return to normothermia & $6.96 \pm 1.24$ & $7.64 \pm 1.15^{\mathrm{a}}$ & $0.623 \pm 0.15$ & $2.86 \pm 0.67^{\mathrm{b}}$ \\
\hline
\end{tabular}

Values are means \pm SEM; a stimulus intensity of three times P1 threshold was used.

${ }^{\mathrm{a}} p<0.01$

${ }^{\mathrm{b}} p<0.05$; as compared with normothermia, Tukey's post hoc test after a significant ANOVA.

$\mathrm{DG}=$ dentate gyrus; $\mathrm{CA} 1=$ cornu ammonis 1 region of the hippocampus; N/A $=$ not applicable, no data collected. 
Hyperthermia Decreased Paired-pulse Inhibition in the Adult Cornu Ammonis 1 Region

of the Hippocampus

Stimulation of CA3 resulted in a positive population EPSP and a negative population spike at the CA1 pyramidal cell layer. A mean threshold stimulus intensity was $27 \pm 2 \mu \mathrm{A}$ for the population EPSP and $151 \pm$ $16 \mu \mathrm{A}$ for P1 $(\mathrm{n}=10)$. Hyperthermia induced a drastic but reversible increase in P2 in CA1 (see Fig 1A). During normothermia, CA1 showed paired-pulse inhibition $(\mathrm{P} 2 / \mathrm{P} 1,<1)$ at less than 100 milliseconds IPI and a small paired-pulse facilitation at greater than 100 milliseconds IPI (Fig 3A). Severe, but not moderate, hyperthermia increased P2/P1 at most IPIs. A repeated measures ANOVA showed that the main effect of temperature on $\mathrm{P} 2 / \mathrm{P} 1$ was significant $\left(\mathrm{F}_{2,10}=5.51 ; p=\right.$ $0.041 ; \mathrm{n}=10$ ) at 20 to 200 milliseconds IPI (see Fig $3 \mathrm{~A})$. Tukey's post hoc test showed a significant increase in $\mathrm{P} 2 / \mathrm{P} 1$ during severe hyperthermia, when compared with normothermia $\left(\mathrm{q}_{4,27}=5.22 ; p<0.01\right)$, with no significant temperature or IPI interaction. At 400 milliseconds IPI, there was a trend of temperature only on $\mathrm{P} 2 / \mathrm{P} 1\left(\mathrm{~F}_{2,12}=4.13 ; p=0.053\right)$. There was no significant difference between normothermia and moderate hyperthermia or between normothermia and "return to normothermia."

The P1 amplitude of the adult hippocampal CA1 decreased progressively with increasing temperature. The effect of temperature on P1 amplitude was significant at a fixed stimulus intensity of three times P1 threshold or across stimulus intensities $\left(\mathrm{F}_{2,6}=7.3\right.$; $p=0.03 ; \mathrm{n}=5)$. The $\mathrm{P} 1$ and $\mathrm{P} 2$ amplitudes in CA1 did not completely recover with the "return to normothermia" (see Table 1). A repeated measures ANCOVA showed that for a given P1 amplitude, there was a significant increase in P2 amplitude during moderate $\left(\mathrm{F}_{1,14}=15 ; p=0.002\right)$ and severe hyperthermia $\left(\mathrm{F}_{1,14}=17.9 ; p=0.001\right)$, as compared with normothermia $(\mathrm{n}=4$; see Fig 3B).

\section{Moderate Hyperthermia Had Minimal Effects on the Dentate Gyrus Field Potentials in Immature Rats}

In the immature DG, the mean thresholds for the population EPSP and the population spike were $29 \pm 8$ and $205 \pm 33 \mu \mathrm{A}$, respectively $(\mathrm{n}=6)$. The threshold was significantly larger than the same measure in the adult DG. In addition, the evoked responses were smaller in the immature as compared with the adult rat (see Fig 1B; Tables 1 and 2).

The relation of P2/P1with IPI in the DG of immature rats (Fig 4A) was similar to that of adult rats, except that paired-pulse inhibition was not found at 400 milliseconds IPI. P2/P1 in the immature rat (see Figs $1 \mathrm{~B}$ and $4 \mathrm{~A}$ ) showed no significant change with temperature $\left(\mathrm{F}_{2,6}=0.521 ; p=0.5\right)$. Although the sample
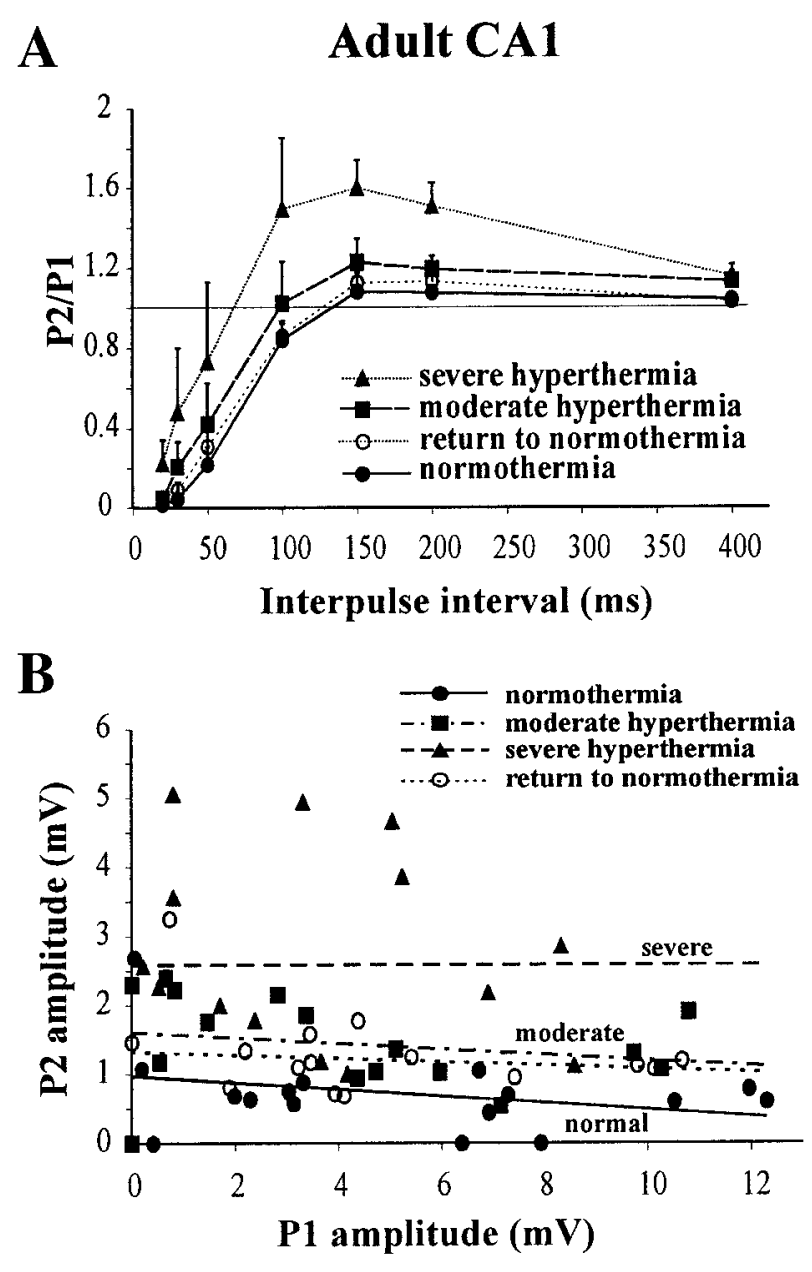

Fig 3. P2 to P1 ratio of the population spikes in the adult cornu ammonis 1 region of the hippocampus (CA1) was decreased during hyperthermia. (A) P2/P1 as a function of IPI; three times P1 threshold paired pulses were delivered to CA3. $P 2$ to $P 1$ ratio was significantly increased during severe hyperthermia at IPIs of 20 to 200 milliseconds, as compared with normothermia. (B) The change in P2 amplitude was independent of P1 amplitude, as shown by a scatter plot of P2 versus P1 (30 milliseconds IPI, three times the P1 threshold stimuli; average of four sweeps) in different conditions in adult CA1. Layout is similar to Fig 2B. A linear regression fit is shown for each of the four conditions: normothermia, moderate hyperthermia, severe hyperthermia, and "return to normothermia." ms $=$ milliseconds.

size was relatively small $(\mathrm{n}=6)$, the null hypothesis (that there is no temperature effect on P2/P1) was not rejected with $p=0.5$, far larger than the normally accepted level of significance $(p<0.05)$. In addition, there was no significant interaction between temperature and IPI $\left(\mathrm{F}_{3,12}=2.67 ; p=0.10\right)$ and no significant change of $\mathrm{P} 1$ amplitude with temperature $\left(\mathrm{F}_{2,6}=\right.$ 3.79; $p=0.108)$. 
Table 2. Effect of Hyperthermia on the Population Excitatory Postsynaptic Potentials (mean \pm SEM) in the DG and CA1 of Adult and Immature Rats

\begin{tabular}{|c|c|c|c|c|}
\hline \multirow[b]{2}{*}{ Effect } & \multicolumn{2}{|c|}{ Adult } & \multicolumn{2}{|c|}{ Immature } \\
\hline & $\mathrm{DG}(\mathrm{n}=7)$ & $\begin{array}{c}\text { CA1 } \\
(\mathrm{n}=9)\end{array}$ & $\begin{array}{c}\mathrm{DG} \\
(\mathrm{n}=6)\end{array}$ & $\begin{array}{c}\text { CA1 } \\
(\mathrm{n}=8)\end{array}$ \\
\hline \multicolumn{5}{|l|}{$\mathrm{E} 1(\mathrm{mV} / \mathrm{msec})$} \\
\hline Normothermia & $5.56 \pm 0.64$ & $1.35 \pm 0.26$ & $0.55 \pm 0.08$ & $0.57 \pm 0.07$ \\
\hline Moderate hyperthermia & $6.14 \pm 0.70^{\mathrm{a}}$ & $1.45 \pm 0.22$ & $0.60 \pm 0.07$ & $0.62 \pm 0.08$ \\
\hline Severe hyperthermia & $6.37 \pm 0.74^{\mathrm{a}}$ & $1.48 \pm 0.22$ & N/A & N/A \\
\hline Return to normothermia & $5.53 \pm 0.77$ & $1.28 \pm 0.25$ & $0.57 \pm 0.09$ & $0.52 \pm 0.06$ \\
\hline \multicolumn{5}{|l|}{$\mathrm{E} 2 / \mathrm{E} 1$} \\
\hline Normothermia & $0.93 \pm 0.02$ & $0.97 \pm 0.11$ & $1.22 \pm 0.16$ & $1.43 \pm 0.18$ \\
\hline Moderate hyperthermia & $0.93 \pm 0.01$ & $0.90 \pm 0.07$ & $1.10 \pm 0.13$ & $1.50 \pm 0.23$ \\
\hline Severe hyperthermia & $0.95 \pm 0.02$ & $1.00 \pm 0.14$ & N/A & N/A \\
\hline Return to normothermia & $0.97 \pm 0.03$ & $0.99 \pm 0.13$ & $1.16 \pm 0.12$ & $1.44 \pm 0.21$ \\
\hline
\end{tabular}

E2 and E1 were measured as shown in Fig 1. Results for the same rats as in Table 1 except rats with small E1 were discarded. Note an E1 increase with temperature, although only significant for the adult DG. E2/E1 did not change significantly with temperature in any structure studied.

${ }^{\mathrm{a}} p<0.01$.

$\mathrm{DG}=$ dentate gyrus; $\mathrm{CA} 1=$ cornu ammonis 1 region of the hippocampus; N/A $=$ not applicable.

\section{Moderate Hyperthermia Decreased Paired-pulse Inhibition in the Immature Cornu Ammonis 1 Region of the Hippocampus}

CA1 responses after CA3 stimulation gave EPSP and P1 thresholds of $38 \pm 5$ and $219 \pm 27 \mu \mathrm{A}$, respectively $(\mathrm{n}=9)$, which were significantly different from the respective thresholds in adult rats. During normothermia in the immature hippocampal CA1, the P2/P1 versus IPI plot was biphasic, as in the adult rat, although paired-pulse facilitation appeared to be more prominent at greater than 30 milliseconds in the immature than adult rat (cf, Figs $4 \mathrm{~B}$ and $3 \mathrm{~A}$ ). In the immature rat shown, an increase in temperature increased P2 amplitude with little change in P1 (see Fig 1B). A repeated measures ANOVA confirmed that moderate hyperthermia increased $\mathrm{P} 2 / \mathrm{P} 1$, as compared with normothermia, and this increase disappeared after returning to normothermia. Using a fixed stimulus intensity of three times the P1 threshold, we found that the temperature effect on $\mathrm{P} 2 / \mathrm{P} 1$ was significant for IPIs of 20 to 200 milliseconds $\left(\mathrm{F}_{2,10}=5.017 ; p=0.048\right.$; $\mathrm{n}=9)$ but not at 400 milliseconds IPI. There was a trend for an interaction between temperature and IPI $\left(\mathrm{F}_{3,21}=2.60 ; p=0.089\right)$. To compare between adult and immature rats without the "severe hyperthermia" group, we performed repeated measures ANOVAs on the P2/P1 data (20-200 milliseconds IPI) that included only two conditions, normothermia and moderate hyperthermia. Similar to the results of the overall ANOVA, a significant temperature effect was found for immature CA1 $\left(\mathrm{F}_{1,8}=5.65 ; p=0.045\right)$ but not for adult CA1 $\left(\mathrm{F}_{1,9}=0.58 ; p=0.15\right)$.

Using a fixed stimulus intensity (three times the P1 threshold), we found that P1 amplitude of the imma- ture hippocampal CA1 decreased significantly with increasing temperature $\left(\mathrm{F}_{2,12}=4.47 ; p=0.048\right)$. The decrease in P1 amplitude was not completely reversible on returning to normothermia $\left(\mathrm{q}_{3,16}=3.11 ; p<\right.$ 0.05 ; see Table 1). For similar P1 amplitudes, the amplitude of P2 in the immature hippocampal CA1 was significantly larger during moderate hyperthermia, as compared with normothermia, using a fixed IPI of 30 milliseconds $\left(\mathrm{F}_{1,23}=4.42 ; p=0.047 ; \mathrm{n}=5\right)$ as measured using repeated measures ANCOVA (data not shown).

\section{Temperature Effects on Excitatory Postsynaptic}

\section{Potentials and Spontaneous Electroencephalogram}

There was a general increase of E1 with temperature, although the increase was significant only for the adult DG $\left(\mathrm{F}_{2,11}=11 ; p=0.003 ; \mathrm{n}=7\right)$, showed a trend for adult CA1 $\left(\mathrm{F}_{2,12}=3.2 ; p=0.09 ; \mathrm{n}=9\right)$, and was not significant for DG $(p>0.3)$ or CA1 $(p>0.16)$ in the immature rat (see Table 2). As a consequence of the E1 increase, hyperthermia decreased P1 onset latency for all groups (see Table 1). The E2 to E1 ratio was not significantly affected by hyperthermia in any group (see Table 2).

There were no spontaneous epileptiform discharges or electroencephalogram depression observed in the DG or CA1 during the hyperthermia experiment, in the adult or immature rat. No evoked population spike bursting was observed during normothermia or hyperthermia.

\section{Discussion}

We did not find spontaneous or evoked paroxysmal activity during hyperthermia in urethane-anesthetized 


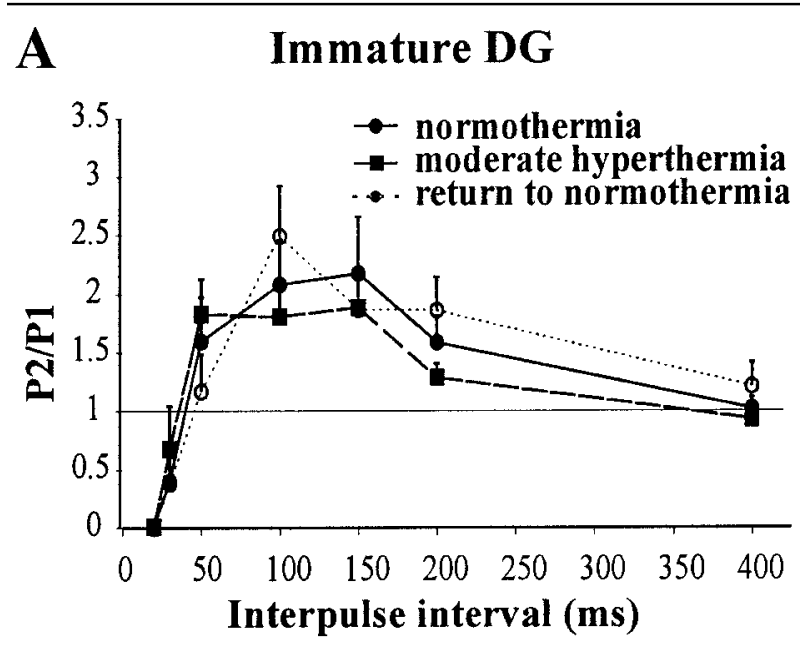

B

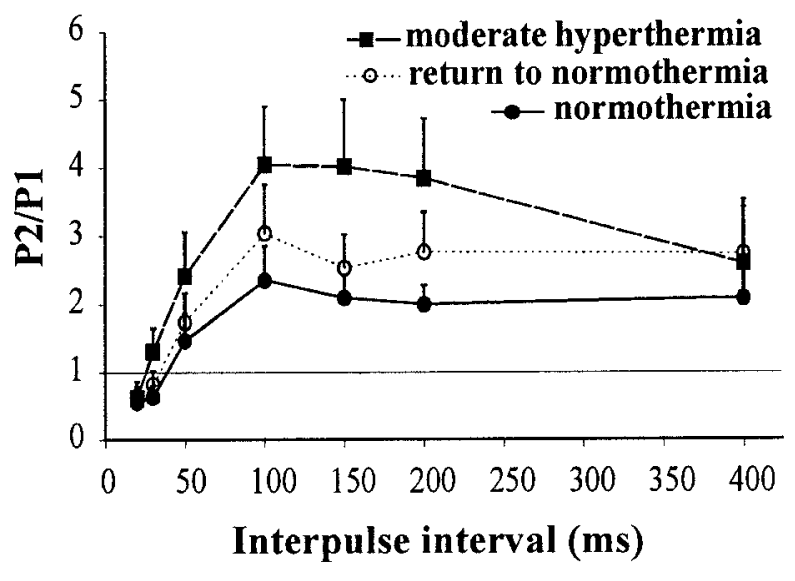

Fig 4. In the immature rat, the ratio of paired-pulse population spikes (P2/P1) was not changed during moderate hyperthermia in the dentate gyrus (DG), but it increased in cornu ammonis 1 region of the hippocampus (CA1). (A) P2/P1 in the $D G$ is plotted as a function of interpulse interval (IPI). There were no significant differences between normothermia and any of the treatments. (B) In hippocampal CA1, P2/P1 was significantly increased during moderate hyperthermia at IPIs of 20 to 200 milliseconds as compared with normothermia. $m s=$ milliseconds.

rats in vivo. Urethane is a powerful anticonvulsant, ${ }^{29}$ and seizure activity was not observed at $42^{\circ} \mathrm{C}$, which would induce febrile convulsions in awake adult or immature rats. ${ }^{9-11}$ Previous in vitro studies also reported spike bursts at 38.2 to $39.2^{\circ} \mathrm{C}$ in immature hippocampal slices ${ }^{30}$ or an age-dependent occurrence of spreading depression. ${ }^{31}$ The smaller inhibition in vitro ${ }^{32}$ than in vivo may have contributed to the latter events.

In general, we found an increase of $\mathrm{E} 1$ and a decrease of P1 amplitude with temperature (see Table 1). This confirms other studies in the $\mathrm{DG}^{12}$ and CA1. ${ }^{13,14}$ An EPSP increase may be attributed to an increase in synaptic release. ${ }^{14,33} \mathrm{~A}$ decrease in population spike amplitude could be attributed to the reduction of amplitude and duration of unitary action potentials with temperature. ${ }^{17,18}$

\section{Changes in GABAergic Inhibition with Temperature}

The amplitude and duration of unitary spikes contribute to both P1 and P2, and thus the P2 to P1 ratio is mainly independent of the changes in unitary spike characteristics. In both DG and CA1, in immature and adult rats, the effect of hyperthermia on the P2 to P1 ratio was shown to be independent of P1 (see Figs 2B and $3 \mathrm{~B})$. Given that the E2 to E1 ratio was not affected by temperature, the change in P2/P1 with temperature can be interpreted as mainly determined by inhibition. Different types of hippocampal interneurons mediate the inhibition, ${ }^{34}$ which consists of early IPSPs attributed to $\mathrm{GABA}_{\mathrm{A}}$ receptors ${ }^{21,22}$ and late IPSPs mediated by $\mathrm{GABA}_{\mathrm{B}}$ receptors. ${ }^{35}$ Paired-pulse inhibition in the DG at 400 milliseconds IPI was observed in the adult ${ }^{35}$ (see Fig 2A) but not the immature (see Fig 4A) rat, confirming previous reports. ${ }^{36,37}$ We suggest that hyperthermia may increase late $\mathrm{GABA}_{\mathrm{B}}$ receptor-mediated IPSP in the adult but not the immature DG, simply because the late IPSP is small in the immature DG. However, late IPSPs in CA1 in vitro were reported to decrease with temperature. ${ }^{21}$ Direct recordings of IPSPs during hyperthermia in vivo will be necessary to verify the suggestion. Other events may contribute to the change in P2/P1. (1) Hypocapnia and alkalosis after hyperventilation (secondary to hyperthermia) appear to have only weak effects on IPSP ${ }^{38,39}$ and may not explain the P2/P1 changes. (2) Spike afterpotential after a single spike is not expected to affect P2/P1. ${ }^{40}$ (3) Blockade of $N$-methyl-Daspartate receptor-mediated EPSPs was reported to decrease $\mathrm{P} 2 / \mathrm{P} 1$ in the $\mathrm{DG}$ of urethane-anesthetized rats, ${ }^{41}$ but this was not found in awake rats (L.S.L., unpublished data). Also, $N$-methyl-D-aspartate receptor blockade did not affect late paired-pulse facilitation in CA1 in vitro. ${ }^{40,42}$ (4) The participation of intrinsic currents, for example, $I_{h}$, in $\mathrm{P} 2 / \mathrm{P} 1$ changes is not known. $\mathrm{I}_{\mathrm{h}}$ activation was increased weeks after a febrile seizure. ${ }^{13}$ However, rebound excitation mediated by $\mathrm{I}_{\mathrm{h}}$ only occurred after a train of IPSPs and not after a single condition pulse. ${ }^{13}$

Changes in paired-pulse inhibition with temperature is different for the DG as compared with the CA1, in either the adult or the immature rat. Differential responses of CA1 and DG to various manipulations have been reported. For example, high extracellular $\left[\mathrm{Ca}^{2+}\right]_{0}$ in vitro increased $\mathrm{E} 2 / \mathrm{E} 1$ in the CA1 but decreased E2/E1 in the DG. ${ }^{43}$ Also, kindling induced a longlasting inhibition increase in the DG but an inhibition decrease in CA1. ${ }^{23,44,45}$ 


\section{Differences between Immature and Mature Rats and Relevance to Febrile Seizures}

Higher stimulus thresholds and smaller population spike and EPSP responses were found in immature rats compared with adult rats, confirming earlier results. ${ }^{37,46}$ In comparison with adult rats, immature rats also showed a smaller late paired-pulse inhibition in the DG and a smaller early inhibition but larger late facilitation in CA1, similar to results reported in the literature. ${ }^{36,37,46}$

The hyperthermia-induced changes in inhibition in the CA1 and the DG may affect seizure generation in the hippocampus. Two original results in this study suggest that the hippocampus is more susceptible to hyperthermic seizure in the immature as compared with the adult rat. First, moderate hyperthermia induced significant disinhibition in CA1 of the immature rat, whereas severe hyperthermia was needed to induce similar CA1 changes in the adult rat. Disinhibition in CA1 may contribute to the onset of a hyperthermiainduced hippocampal seizure, which may then propagate outside the hippocampus. ${ }^{47}$ Second, compensatory increase in inhibition in the DG with hyperthermia occurred in the adult but not immature rat. Thus, the DG may serve as a powerful gate ${ }^{48,49}$ for suppressing seizures in the hyperthermic condition, but only in the adult rat.

The above suggestion is speculative because seizure activity was not induced in this study. However, the differential changes of paired-pulse inhibition in different regions of the hippocampus are potentially important factors that control the initiation of hippocampal seizures during hyperthermia.

This work was supported by operating grants from the Medical Research Council (MOP-36421, L.S.L.), the Natural Sciences and Engineering Research Council of Canada (1037-98 RGPIN, L.S.L.), an internal research grant from London Health Sciences Centre (L.S.L.), and by an Ontario Graduate Scholarship and a summer studentship from Epilepsy Canada (M.T.L.).

We thank Bixia Shen for technical assistance, Dr Rajakumar for his loan of the infant rat stereotaxic frame accessories, and Dr Cain for comments on an earlier draft of this report.

This study was previously presented in part at the 29th Annual Society for Neuroscience Meeting, Miami Beach.

\section{References}

1. Holmes GL, Ben-Ari Y. Seizures in the developing brain: perhaps not so benign after all. Neuron 1998;21:1231-1234.

2. van den Berg BJ, Yerushalmy J. Studies on convulsive disorders in young children. Pediatr Res 1969;3:298-304.

3. Nelson KB, Ellenburg JH. Prognosis in children with febrile seizures. Pediatrics 1978;61:720-727.

4. Berg AT, Shinnar S. Do seizures beget seizures? Assessment of the clinical evidence in humans. J Clin Neurophysiol 1997;14: $102-110$.
5. Rocca WA, Sharbrough FW, Hauser WA, et al. Risk factors for complex partial seizures: a population-based case-control study. Ann Neurol 1987;21:22-31.

6. Maher J, McLachlan RS. Febrile convulsions. Is seizure duration the most important predictor of temporal lobe epilepsy. Brain 1995;118:1521-1528.

7. VanLandingham KE, Heinz ER, Cavazos JE, et al. Magnetic resonance imaging evidence of hippocampal injury after prolonged focal febrile convulsions. Ann Neurol 1998;43: 413-426.

8. Baram TZ, Gerth A, Schultz L. Febrile seizures: an appropriateaged model suitable for long-term studies. Dev Brain Res 1997; 98:265-270.

9. Holtzman D, Oban K, Olson J. Hyperthermia-induced seizures in the rat pup: a model for febrile convulsions in children. Science 1981;213:1034-1036.

10. McCaughran JA Jr, Schechter N. Experimental febrile convulsions: long-term effects of hyperthermia-induced convulsions in the developing rat. Epilepsia 1982;23:173-183.

11. Dube C, Chen K, Eghbal-Ahmadi M, et al. Prolonged febrile seizures in the immature rat model enhance hippocampal excitability long term. Ann Neurol 2000;47:336-344.

12. Chen K, Baram TZ, Soltesz I. Febrile seizures in the developing brain result in persistent modification of neuronal excitability in limbic circuits. Nat Med 1999;5:888-894.

13. Chen K, Aradi I, Thon N, et al. Persistent modified h-channels after complex febrile seizures convert the seizure-induced enhancement of inhibition to hyperexcitability. Nat Med 2001;7: 331-337.

14. Kornelsen RA, Boon F, Leung LS, et al.. The effects of a single neonatally induced convulsion on spatial navigation, locomotor activity and convulsion susceptibility in the adult rat. Brain Res 1996; 106:155-159.

15. Toth Z, Yan X-X, Haftoglou S, et al. Seizure-induced neuronal injury: vulnerability to febrile seizures in an immature rat model. J Neurosci 1998;18:4285-4284.

16. Jiang W, Duong TM, de Lanerolle NC. The neuropathology of hyperthermic seizures in the rat. Epilepsia 1999;40:5-19.

17. Moser E, Mathiesen I, Andersen P. Association between brain temperature and dentate field potentials in exploring and swimming rats. Science 1993;259:1324-1326.

18. Shen K, Schwartzkroin PA. Effects of temperature alterations on population and cellular activities in hippocampal slices from mature and immature rabbit. Brain Res 1988;475:305-316.

19. Schiff SJ, Somjen GG. The effects of temperature on synaptic transmission in hippocampal tissue slices. Brain Res 1985;345: 279-284.

20. Andersen P, Bliss TVP, Skrede KK. Unit analysis of hippocampal population spikes. Exp Brain Res 1971;13:208-221.

21. Thompson SM, Masukawa LM, Prince DA. Temperature dependence of intrinsic membrane properties and synaptic potentials in hippocampal CA1 neurons in vitro. J Neurosci 1985;5: 817-824.

22. Steffensen SC, Henriksen SJ. Effects of baclofen and bicuculline on inhibition in the fascia dentate and hippocampus regio superior. Brain Res 1991;538:46-53.

23. Tuff LP, Racine RJ, Adamec R. The effects of kindling on GABA-mediated inhibition in the dentate gyrus of the rat. I. Paired-pulse depression. Brain Res 1983;277:79-90.

24. Liebregts MT, McLachlan RS, Leung LS. Effects of hyperthermia on hippocampal excitability in the urethane anesthetised adult rat. Soc Neurosci Abstr 1999;25:1607.

25. Dobbing J, Sands J. Quantitative growth and development of human brain. Arch Dis Child 1973;48:757-767.

26. Paxinos G, Watson C. The rat brain in stereotaxic coordinates. 2nd ed. San Diego: Academic Press, 1986. 
27. Sherwood NM, Timiras PS. A stereotaxic atlas of the developing rat brain. Berkeley: University of California Press, 1970.

28. Leung LS, Roth L, Canning K. Entorhinal inputs to the hippocampal CA1 and dentate gyrus in the rat: a current-sourcedensity study. J Neurophysiol 1995;73:2392-2403.

29. Cain DP, Raithby A, Corcoran ME. Urethane anesthesia blocks the development and expression of kindled seizures. Life Sci 1989;44:1201-1206.

30. Tancredi V, D'Arcangelo G, Zona C, et al. Induction of epileptiform activity by temperature elevation in hippocampal slices from young rats: an in vitro model for febrile seizures? Epilepsia 1992;33:228-234.

31. Wu J, Fisher RS. Hyperthermic spreading depressions in the immature rat hippocampal slice. J Neurophysiol 2000;84: $1355-1360$.

32. Buckmaster PS, Schwartzkroin PA. Interneurons and inhibition in the dentate gyrus of the rat in vivo. J Neurosci 1995;15: $774-789$.

33. Katz B, Miledi R. The effect of temperature on the synaptic delay at the neuromuscular junction. J Physiol 1965;181: 656-670.

34. Freund TF, Buzsaki G. Interneurons of the hippocampus. Hippocampus 1996;6:347-470.

35. Canning KJ, Leung LS. Excitability of rat dentate gyrus granule cells in vivo is controlled by tonic and evoked $\mathrm{GABA}_{\mathrm{B}}$ receptormediated inhibition. Brain Res 2000;86:271-275.

36. Bekenstein JW, Lothman EW. A comparison of the ontogeny of excitatory and inhibitory neurotransmission in the CA1 region and dentate gyrus of the rat hippocampal formation. Dev Brain Res 1991;63:237-243.

37. Bronzino JD, Blaise JH, Austin-LaFrance RJ, et al. Studies of dentate granule cell modulation: paired-pulse responses in freely moving rats at three ages. Dev Brain Res 1996;96: 277-280.
38. Kaila K, Lamsa K, Smirnov S, et al. Long-lasting GABAmediated depolarization evoked by high frequency stimulation in pyramidal neurons of rat hippocampal slice is attributable to a network-driven, bicarbonate-dependent $\mathrm{K}^{+}$transient. J Neurosci 1997; 17:7662-7672.

39. Balestrino M, Somjen GG. Concentration of carbon dioxide, interstitial $\mathrm{pH}$ and synaptic transmission in hippocampal formation of the rat. J Physiol 1988;396:247-266.

40. Leung LS, Fu X-W. Factors affecting paired-pulse facilitation in CA1 neurons in vitro. Brain Res 1994;650:75-84.

41. Joy RM, Albertson TE. NMDA receptors have a dominant role in population spike-paired pulse facilitation in the dentate gyrus of urethane-anesthetized rats. Brain Res 1993;604:273-282.

42. Nathan T, Jensen MS, Lambert JDC. $G_{A B A}$ receptors play a major role in paired-pulse facilitation in area CA1 of the rat hippocampus. Brain Res 1990;531:55-65.

43. Turner RW, Miller JJ. Effects of extracellular calcium on low frequency induced potentiation and habituation in the in vitro hippocampal slice preparation. Can J Physiol Pharmacol 1982; 60:266-275.

44. Mody I, Staley KJ. Cell properties in the epileptic hippocampus. Hippocampus 1994;4:275-280.

45. Zhao D, Leung LS. Hippocampal kindling induced pairedpulse depression in the dentate gyrus and paired-pulse facilitation in CA3. Brain Res 1992;582:163-167.

46. Michelson HB, Lothman EW. An in vivo electrophysiological study of the ontogeny of excitatory and inhibitory processes in the rat hippocampus. Dev Brain Res 1989;47:113-122.

47. Lopes da Silva FH, Witter MP, Boeijinga P, et al. Anatomical organization and physiology of the limbic cortex. Physiol Rev 1990;70:453-511.

48. Heinemann U, Beck H, Dreier JP, et al. The dentate gyrus as a regulated gate for propagation of epileptiform activity. Epilepsy Res Suppl 1992;7:273-280.

49. Lothman EW, Stringer JL, Bertram EH. The dentate gyrus as a control point for seizures in the hippocampus and beyond. Epilepsy Res Suppl 1992;7:301-313. 